\title{
PEMANFAATAN BETADINE SEBAGAI INDIKATOR UJI KLORIN PADA BERAS BERPEMUTIH
}

\section{UTILIZATION OF BETADINE AS A CHLORINE TEST INDICATOR ON WHITE RICE}

\author{
Nyoman Sudarma, Sri Idayani, Didik Setiawan, Putu Oka Dharmawan. \\ Program Studi Analis Kesehatan STIKes Wira Medika Bali
}

\begin{abstract}
ABSTRAK
Klorin merupakan salah satu penggunaan Bahan Makanan Tambahan yang dilarang. Menurut Peraturan Menteri Kesehatan Republik Indonesia No.033/Menkes/Per/IX/2012, bahwa klorin tidak tercatat sebagai Bahan Tambahan Pangan (BTP) dalam kelompok pemutihan dan pematang tepung. Klorin digunakan sebagai pemutih beras yang dimaksudkan agar beras memiliki kualitas super dengan harga yang tinggi. Masyarakat akan kesulitan membedakan beras yang mengandung klorin atau tidak sehingga perlu dilakukan uji sederhana yang dapat dilakukan oleh masyarakat luas. Povidon iodine atau dikenal dengan betadine yang merupakan bahan antiseptik luka merupakan salah satu alternatif digunakan untuk identifikasi secara kualitatif kandungan klorin baik pada makanan maupun air. Tujuan dari penelitian ini adalah untuk mengetahui apakah betadine dapat digunakan sebagai alternatif untuk identifikasi klorin pada sampel beras bermerk maupun non merk. Hasil penelitian menunjukkan bahwa betadine dapat digunakan sebagai indikator identifikasi klorin pada sampel beras yang dijual di pasaran. Sepuluh sampel beras yang diidentifikasi dua diantaranya terindikasi positif mengandung pemutih klorin. Sampel beras positif mengandung klorin jika setelah penambahan dengan betadine menghasilkan warna putih keruh. Uji penegasan dilakukan dengan menambahkan larutan amilum dan KI 10\% pada sampel beras dan menghasilkan warna biru kehitaman.
\end{abstract}

Kata kunci : beras, pemutih, klor, betadine

\section{ABSTRACT}

Chlorine is one of the prohibited uses of Foodstuffs. According to the Regulation of the Minister of Health of the Republic of Indonesia No.033 / Menkes / Per / IX / 2012, that chlorine is not recorded as a Food Additives (BTP) in the bleaching and flour milling group. Chlorine is used as rice bleach which is intended to have a super quality rice at a high price. The community will find it difficult to distinguish whether or not rice contains chlorine or not, so a simple test can be carried out by the community. Povidon iodine, also known as betadine, which is an antiseptic wound, is one alternative used to qualitative identify chlorine content in food and water. The purpose of this study was to determine whether betadine can be used as an alternative for identification of chlorine in samples of branded and non-branded rice. The results showed that betadine could be used as an indicator of chlorine identification in rice samples sold in the market. Ten rice samples were identified, two of which were indicated to be positive for chlorine bleach. The rice sample is 
positive for chlorine if after adding it with betadine it produces a cloudy white color. The affirmation test was carried out by adding a solution of starch and $10 \% \mathrm{KI}$ to the rice sample and producing a blackish blue color.

\section{Key words: rice, bleach, chlorine, betadine}

\begin{tabular}{ll}
\hline Alamat Korespondensi & $\begin{array}{l}\text { : Jalan Tukad Balian Renon Gang } 2 \text { No } 10 \text { Denpasar Selatan } \\
\text { Email }\end{array}$ \\
\hline
\end{tabular}

\section{PENDAHULUAN}

Keamanan pangan merupakan faktor terpenting yang harus diperhatikan untuk mendapatkan makanan yang bebas dari kerusakan, pemalsuan dan kontaminasi, baik yang disebabkan oleh mikroba atau senyawa kimia. Keamanan makanan merupakan salah satu masalah yang harus mendapatkan perhatian terutama di negara berkembang seperti Indonesia, karena bisa berdampak buruk terhadap kesehatan. Penyebabnya adalah masih rendahnya pengetahuan, keterampilan serta tanggung jawab daripada produsen dan distributor pangan terhadap mutu serta keamanan makanan (Yude, 2016).

Beras merupakan bahan makanan yang dapat memberikan sumber energi bagi manusia. Beras yang baik adalah beras yang dapat menghasilkan nasi yang empuk dan dapat memberikan aroma yang harum. Nasi merupakan salah satu makanan pokok yang mudah diolah dan disajikan dengan enak, mengandung energi yang cukup tinggi sehingga berpengaruh besar terhadap aktivitas tubuh (Sinuhaji,2009). Dari khasiat yang terkandung pada beras, tidak jarang produsen menggunakan bahan tambahan pangan dengan tujuan memperpanjang masa simpan atau memperbaiki tekstur, citarasa dan warna (Yude, 2016). Hal ini menyebabkan produsen dan distributor sering menambahkan bahan kimia ke dalam produk makanan, salah satunya penambahan klorin pada beras yang bersifat merugikan dan membahayakan konsumen (Direktorat Jenderal Pengawasan Obat Dan Makanan Departemen Kesehatan Republik Indonesia,1979).

Penelitian yang dilakukan oleh Dinas Perindag, Balai Pengawasan Obat dan Makanan (BPOM) serta Balai Pengujian dan Sertifikasi Mutu Barang (BPSBM) Sumatera Utara menemukan 1 dari 19 sampel beras yang diambil dari pengecer, gudang beras, serta kilang padi di Medan, Deli Serdang, dan Serdang Bedagai, positif mengandung klorin. Di lain pihak, Balai Pengawasan Obat dan Makanan Kota Tanggerang menemukan kadar klorin seberat 0,05 ppm dalam beras curah yang diperdagangkan di pasar tradisional Tanggerang. Berdasarkan hasil penelitian Dinas Kesehatan Kota Tangerang menyatakan bahwa klorin pada beras akan tetep melekat sampai beras telah dimasak menjadi nasi hanya saja kadarnya yang berkurang (Stefi,2007). Pernyataan tersebut diperkuat oleh adanya penelitian Sinuhaji (2009) yang melakukan pengukuran kadar klorin pada beras hingga beras diolah menjadi nasi. Hasil penelitiannya menyimpulkan bahwa terjadinya penurunan kadar klorin pada beras hingga menjadi nasi yaitu dari 45,361 ppm turun menjadi 3,488 ppm pada suhu kamar $\left( \pm 25^{\circ} \mathrm{C}\right)$. Meskipun terjadi penurunan kadar klorin tetap saja pada nasi yang akan dikonsumsi masih mengandung klorin. 
Klorin merupakan salah satu penggunaan Bahan Makanan Tambahan yang dilarang. Menurut Peraturan Menteri Kesehatan Republik Indonesia No.033/Menkes/Per/IX/2012, bahwa klorin tidak tercatat sebagai Bahan Tambahan Pangan (BTP) dalam kelompok pemutihan dan pematang tepung. Klorin digunakan sebagai pemutih beras yang dimaksudkan agar beras memiliki kualitas super dengan harga yang tinggi. Klorin adalah bahan kimia yang biasanya digunakan sebagai desinfektan, pemutih kertas dan proses tekstil (Sinuhaji, 2009). Klorin juga digunakan sebagai bahan kimia pereaksi dalam pabrik logam klorida, bahan pelarut klorinasi, pestisida, polimer, karet sintetis dan refrigetan. Sodium hipoklorit merupakan komponen pemutih yang digunakan sebagai larutan pembersih, dan desinfektan untuk air minum serta sistem penyaringan limbah dan kolam renang (Rahmi,2016). Klorin akan bereaksi dengan air dan membentuk asam hipoklorus yang apabila masuk ke dalam tubuh manusia akan merusak sel-sel tubuh.

Klorin yang terdapat pada beras akan bersifat korosif sehingga akan merusak lambung. Dalam jangka panjang, klorin akan mengakibatkan penyakit kanker dan gangguan ginjal. Berdasarkan penelitian Norlatifah (2012), dampak yang ditimbulkan oleh klorin tergantung pada kadar, jenis senyawa klorin dan yang terpenting tingkat toksisitas senyawa tersebut. Pengaruh klorin pada kesehatan dapat menggganggu system kekebalan tubuh, merusak hati dan ginjal, gangguan pencernaan, gangguan pada sistem saraf, dapat menyebabkan kanker dan gangguan sistem reproduksi yang dapat menyebabkan keguguran. Dalam bentuk gas, klor dapat merusak membranmukus dalam wujud cair, dapat menghacurkan kulit.Tingkat klorida sering naik turun bersama dengan tingkat natrium. Ini karena natrium klorida atau garam merupakan unsur utama dalam darah (Sartono,2012).

Tilawati (2015) melakukan identifikasi pada sampel beras yang diambil di pasar tradisional Klepu menyebutkan bahwa dari 8 merk sampel beras yang diuji didapatkan 2 sampel beras yang positif mengandung klorin dengan kadar 17,51 $\mathrm{mg} / \mathrm{L}$ dan 18,11 mg/L. Penelitian dilanjutkan oleh Hanifah (2015) dengan mengambil sampel beras di pasar Tanjng Kabupaten Jember. Dari 17 sampel beras yang diidentifikasi didapatkan 5 sampel beras yang positif mengandung klorin dengan kadar tertinggi $12,31 \mathrm{mg} / \mathrm{L}$ dan terendah 3,34 mg/L. Berdasarkan penelitian Hanifah (2015) ciri-ciri fisik beras yang mengandung klorin yaitu beras yaituberas berwarna putih bening, bila dipegang beras terasa licin dan ditangan tidak meninggalkan bekas ataupun sisa beras, dan saat beras dicuci air hasil cucian beras berwarna agak putih bersih dan tidak keruh.

Berdasarkan penelitian di atas maka perlu dilakukan penelitian kembali mengenai kandungan klorin pada beras. Uji kualitatif dan kuantitatif adanya klorin dapat dilakukan dengan berbagai metode. Beberapa metode seperti iodometri (Ulfa,2015), argentometri (Tilawati,dkk, 2015) dan spektrofotometri (Silaban, 2013) dapat dilakukan, akan tetapi metode tersebut membutuhkan alat dan bahan yang tentunya ada di laboratorium dan mahal harganya. Povidon iodine adalah salah satu alternatif digunakan untuk identifikasi secara kualitatif kandungan klorin baik pada makanan maupun air. Povidon iodin atau dikenal sebagai betadine merupakan obat luka atau antiseptik yang mampu membunuh mikroorganisme penyebab infeksi baik gram positif, gram negatif, maupun yang resisten terhadap antibiotik (Rahmawati, 2014). Kandungan utama dari betadine adalah iodine, dimana iodine ini juga merupakan salah satu indikator yang dapat digunakan sebagai identifikasi ada atau tidaknya klorin. Oleh karena itu, dalam penelitian ini 
telah dilakukan penggunaan betadine dalam identifikasi klorin pada beras sehingga diharapkan dapat digunakan oleh masyarakat luas karena pemeriksaannya yang sederhana dan tidak memerlukan biaya yang tinggi.

\section{BAHAN DAN METODE}

Sampel beras yang digunakan adalah beras bermerk dan non merk yang dijual dipasaran kemudian dianalisis kandungan klorin di Laboratorium Kimia STIKes Wira Medika Bali

Populasi yang digunakan dalam penelitian ini adalah seluruh merk beras yang dijual di Pasar. Teknik pengambilan sampel adalah total sampling. Total sampling adalah teknik pengambilan sampel dimana jumlah sampel sama dengan populasi (Sugiyono,2017), sehingga sampel merupakan keseluruhan dari populasi.

\section{Alat}

Alat yang digunakan pada penelitian ini adalah kantong plastik ukuran $1 / 4 \mathrm{~kg}$, tabung reaksi, plat tetes, buret $50 \mathrm{ml}$, Erlenmeyer $250 \mathrm{ml}$, gelas beaker $250 \mathrm{ml}$, pipet volume $100 \mathrm{ml}$, pipet ukur $100 \mathrm{ml}$, bola hisap, kertas saring, corong kaca, pipet tetes, aluminium foil.

\section{Bahan}

Bahan yang digunakan pada penelitian ini adalah betadine $50 \mathrm{ml}$, KI 10\%, asam asetat glacial, larutan Natrium Tiosulfat, indikator amilum.

\section{Identifikasi kualitatif klorin pada beras dengan betadine}

1.Sampel beras ditimbang sebanyak $10 \mathrm{~g}$.

2.Sampel ditambahkan dengan $50 \mathrm{ml}$ akuades bebas klor ke dalam Erlenmeyer kemudian ditutup dengan aluminium foil dan sampel diaduk.

3.Sampel kemudian disaring dan diambil filtratnya sebanyak $10 \mathrm{ml}$. 4.Sebanyak $2 \mathrm{ml}$ filtrat ditambahkan dengan 1 tetes betadine.

5.Bila klorin positif maka filtrat akan tetap berwarna putih keruh.

\section{Identifikasi kualitatif klorin pada beras dengan dengan indikator amilum}

1.Sampel beras ditimbang sebanyak $10 \mathrm{~g}$.

2.Sampel ditambahkan dengan $50 \mathrm{ml}$ akuades bebas klor ke dalam Erlenmeyer kemudian ditutup dengan aluminium foil dan sampel diaduk.

3.Sampel kemudian disaring dan diambil filtratnya sebanyak $10 \mathrm{ml}$.

4.Sebanyak $2 \mathrm{ml}$ filtrat ditambahkan dengan $0,5 \mathrm{ml}$ larutan $\mathrm{KI} 10 \%$ dan 5 tetes larutan amilum $1 \%$.

5.Bila klorin positif maka filtrat akan berwarna biru kehitaman 
HASIL

Berdasarkan hasil analisis dapat dilihat pada Tabel 1.

Tabel 1 Hasil Identifikasi klorin secara kualitatif

\begin{tabular}{|c|c|c|c|c|c|}
\hline \multirow[t]{2}{*}{ No } & \multirow[t]{2}{*}{ Sampel } & \multicolumn{2}{|c|}{ Amilum + KI 10\% } & \multicolumn{2}{|c|}{ Betadine } \\
\hline & & $\begin{array}{c}\text { Hasil } \\
\text { pengamata } \\
\mathbf{n}\end{array}$ & $\begin{array}{c}\text { Intepret } \\
\text { asi }\end{array}$ & $\begin{array}{c}\text { Hasil } \\
\text { Pengamatan }\end{array}$ & Intepretasi \\
\hline 1 & $\begin{array}{c}\text { Kontrol } \\
(+)\end{array}$ & $\begin{array}{c}\text { biru } \\
\text { kehitaman }\end{array}$ & $\begin{array}{l}\text { Positif } \\
(+)\end{array}$ & putih keruh & Positif (+) \\
\hline 2 & $\begin{array}{c}\text { Kontrol } \\
(-)\end{array}$ & putih keruh & $\begin{array}{c}\text { Negatif } \\
(-)\end{array}$ & $\begin{array}{c}\text { biru } \\
\text { kehitaman }\end{array}$ & Negatif (-) \\
\hline 3 & A & biru & $\begin{array}{c}\text { Positif } \\
(+)\end{array}$ & putih keruh & Positif $(+)$ \\
\hline 4 & B & putih keruh & $\begin{array}{l}\text { Negatif } \\
(-)\end{array}$ & $\begin{array}{c}\text { biru } \\
\text { kehitaman }\end{array}$ & Negatif (-) \\
\hline 5 & $\mathrm{C}$ & putih keruh & $\begin{array}{l}\text { Negatif } \\
(-)\end{array}$ & $\begin{array}{c}\text { biru } \\
\text { kehitaman }\end{array}$ & Negatif (-) \\
\hline 6 & $\mathrm{D}$ & putih keruh & $\begin{array}{l}\text { Negatif } \\
(-)\end{array}$ & $\begin{array}{c}\text { biru } \\
\text { kehitaman }\end{array}$ & Negatif (-) \\
\hline 7 & $\mathrm{E}$ & putih keruh & $\begin{array}{l}\text { Negatif } \\
(-)\end{array}$ & $\begin{array}{c}\text { biru } \\
\text { kehitaman }\end{array}$ & Negatif (-) \\
\hline 8 & $\mathrm{~F}$ & putih keruh & $\begin{array}{l}\text { Negatif } \\
(-)\end{array}$ & $\begin{array}{c}\text { biru } \\
\text { kehitaman }\end{array}$ & Negatif (-) \\
\hline 9 & G & putih keruh & $\begin{array}{l}\text { Negatif } \\
(-)\end{array}$ & $\begin{array}{c}\text { biru } \\
\text { kehitaman }\end{array}$ & Negatif (-) \\
\hline 10 & $\mathrm{H}$ & putih keruh & $\begin{array}{l}\text { Negatif } \\
(-)\end{array}$ & $\begin{array}{c}\text { biru } \\
\text { kehitaman }\end{array}$ & Negatif (-) \\
\hline 11 & I & putih keruh & $\begin{array}{l}\text { Negatif } \\
(-)\end{array}$ & $\begin{array}{c}\text { biru } \\
\text { kehitaman }\end{array}$ & Negatif (-) \\
\hline 12 & $\mathrm{~J}$ & biru & $\begin{array}{c}\text { Positif } \\
(+)\end{array}$ & putih keruh & Positif $(+)$ \\
\hline
\end{tabular}

Keterangan:

A,D,E,J : beras tidak bermerk

$\mathrm{B}, \mathrm{C}, \mathrm{E}, \mathrm{F}, \mathrm{G}, \mathrm{H}, \mathrm{I}$ : beras bermerk

PEMBAHASAN

Identifikasi pemutih klorin dilakukan secara kualitatif dengan 2 metode yaitu pertama dengan penambahan larutan amilum dan KI 10\%, dan yang kedua adalah dengan menambahkan larutan betade. Pengujian kontrol dilakukan dengan kontrol positif dan kontrol negatif. Ketika kontrol negatif ditetesi dengan larutan betadine diperoleh larutan berwarna kuning kecoklatan. Sedangkan pada kontrol positif setelah ditambahkan dengan larutan betadine didapatkan hasil putih keruh. Pengujian kontrol juga dilakukan dengan menggunakan uji amilum dan KI 10\%. Kontrol negatif setelah ditambahkan dengan amilum dan KI $10 \%$ menunjukkan 
warna putih keruh, sedangkan pada kontrol positif menunjukkan warna biru kehitaman.

Hasil pengujian dengan betadine dari 10 sampel beras yang diperiksa, dua sampel terindikasi positif mengandung pemutih klorin yaitu sampel A dan J. Hal ini dapat dilihat dari warna yang terbentuk yaitu warna putih keruh sesuai dengan kontrol positif. Uji penegas dilakukan dengan menggunakan larutan amilum dan KI $10 \%$, dimana sampel A dan J menunjukkan warna biru kehitaman yang artinya bahwa sampel A dan J terindikasi mengandung pemutih klorin.

Secara normal, larutan betadine bercampur dengan larutan sampel beras yang tidak mengandung pemutih klorin akan menghasilkan warna biru kehitaman. Hal tersebut diakibatkan oleh adanya ikatan yang terjadi antara $\mathrm{I}_{2}$ yang terkandung pada betadine dengan zat tepung (karbohidrat) pada beras membentuk kompleks warna biru kehitaman. Berbeda halnya terjadi pada sampel beras yang mengandung pemutih klorin menunjukkan warna putih keruh. Hal tersebut disebabkan karena $\mathrm{I}_{2}$ yang terkandung pada betadine terhalangi oleh klorin pada beras, sehingga $\mathrm{I}_{2}$ tidak mampu berikatan dengan amilum. Hal ini dibuktikan terbentuknya warna kuning kecoklatan pada kontrol negatif, dan warna putih keruh pada kontrol positif.

Identifikasi dengan menggunakan larutan amilum dan KI $10 \%$ menunjukkan perubahan warna yang terbalik dengan penggunaan betadine. Sampel beras yang mengandung pemutih klorin akan membentuk warna biru. Hal ini disebabkan karena klorin pada beras akan mengoksidasi KI menghasilkan $\mathrm{I}_{2}$ yang kemudian bereaksi dengan larutan amilum sehingga menghasilkan kompleks biru kehitaman.

Tujuan penambahan klorin pada beras adalah untuk membuat beras menjadi lebih putih dan mengkilap agar beras yang berstandar medium terlihat seperti beras yang berkualitas super (Departemen Luar Negeri Republik Indonesia,2007). Konsumen akan sulit membedakan antara beras yang mengandung zat pemutih dengan yang tidak mengandung zat pemutih. Ciri - ciri beras yang diperkirakan mengandung pemutih klorin (pada sampel A dan J) yaitu memiliki warna yang sangat putih bersih, mengkilat, dan licin jika disentuh tangan. Stefi (2007) menyebutkan ciri-ciri beras yang mengandung pemutih klorin yang lain yaitu jika beras dicuci, warna air hasil cuciannya agak putih bersih. Jika beras direndam dalam air selama 3 hari tetap putih dan tidak berbau, dan ketika sudah dimasak dan ditaruh dalam penghangat nasi dalam semalam nasi sudah menimbulkan bau tidak sedap.

Food drug administration (FDA) menetapkan kadar klorin yang diperoleh pada pangan yaitu tidak boleh melebihi 0,82 gram natrium hipoklorit atau 0,36 gram kalsium hipoklorit dalam 100 gram makanan. Penelitian klorin pada beras dilakukan berdasarkan Permenkes No. 722/Menkes/Per/XI/1988 tentang Bahan Tambahan Makanan (BTM) disebutkan bahwa klorin tidak tercatat sebagai Bahan Tambahan Pangan (BTP) dalam kelompok pemutih dan pematang tepung dan tidak boleh digunakan dalam pembuatan bahan makanan (U.S Departemen Of Health And Service, 2007). Menurut Adiwisastra (1989) klorin dalam tubuh manusia dapat menganggu kesehatan, dapat menyebabkan penyakit maag dalam jangka pendek dan dalam jangka panjang secara akumulatif akan menyebabkan penyakit kanker hati dan ginjal. Oleh karena itu, masyarakat harus lebih teliti dalam memilih beras putih yang aman di konsumsi mengingat beras putih merupakan makanan pokok di Indonesia yang setiap hari di konsumsi sehingga efek klorin dapat menganggu kesehatan. 


\section{SIMPULAN DAN SARAN}

\section{Simpulan}

Berdasarkan hasil penelitian maka dapat ditarik simpulan sebagai berikut :

1. Betadine dapat digunakan untuk uji alternatif identifikasi klorin pada beras, dimana beras yang positif mengandung pemutih klorin akan menunjukkan warna putih keruh setelah ditambahkan dengan larutan betadine.

2. Sepuluh sampel beras yang berada dipasaran terindikasi 2 sampel beras positif mengandung pemutih klorin.

\section{Saran}

1. Untuk masyarakat harus pintar memilih beras yang akan digunakan untuk konsumsi agar tidak mendapatkan beras yang mengandung pemutih klorin mengingat bahaya yang dihasilkan terhadap kesehatan.

2. Untuk masyarakat dapat menggunakan betadine sebagai identifikasi klorin pada beras karena selain harga yang murah hasil uji juga dapat dipercaya.

\section{DAFTAR PUSTAKA}

Departemen Luar Negeri Republik Indonesia. 2007. Beras Jernih dan Licin Bahayan Kesehatan Lambung.

Hanifah,N.2015.Kandungan Klorin Pada Beras Putih Di Pasar Tanjung Kabupaten Jember.Skripsi.Kesehatan Lingkungan Dan Kesehatan Keselamatan Kerja Fakultas Kesehatan Masyarakat. Universitas Jember

Norlatifah, 2012.Identifikasi Klorin secara Kualitatif Pada Beras Yang di Jual di Pasar Besar Kecamatan Pahandut Palangka Raya. Universitas Sumatra Utara, Medan.

Rahmawati,I. 2014. Perbedaan Efek Perawatan Luka Menggunakan Gerusan Daun Petai Cina (Leucaena glauca, Benth) dan Povidon Iodine 10\% Dalam Mempercepat Penyembuhan Luka Bersih Pada Marmut (Cavia porcellus). Jurnal Wiyata. Vol.1.No.2

Rahmi,S. 2016. Identifikasi Kualitatif Klorin Pada Beras Yang Diperjualbelikan Di Pasar. Universitas Muslim Nusantara. Medan.Vol.2.No.1

Silaban,S. 20013. Analisis Kandungan Klorin Pada Air The Celup Berdasarkan Suhu Dan Waktu Pencelupan Di Kota Medan Tahun 2013. Skripsi. Fakultas Kesehatan Masyarakat. Universitas Sumatera Utara

Sinuhaji. D.N., 2009. Perbedaan Kandungan Klorin (Cl2) Pada Beras Sebelum dan Sesudah Dimasak Tahun 2009. Skripsi, Medan: Universitas Sumatera Utara.

Stefi. 2007. Beras putih berpemutih. Jakarta: Penerbit Bhratara

Sugiyono. 2017. Metode Penelitian Kuantitatif Kualitatif dan R\&D. Bandung: Alfabeta

Tilawati,W.,Anita,A.,Muchson,A. 2015. Identifikasi dan Penetapan Kadar Klorin Dalam Beras Putih di Pasar Tradisional Klepu Dengan Metode Argentometri. Cerata

Ulfa,AM. 2015. Penetapan Kadar Klorin $\left(\mathrm{Cl}_{2}\right)$ Pada Beras Menggunakan Metode Iodometri. Jurnal Kesehatan Holistic. 9(4):197-200

U.S. Depatemen Of Health And Human Service. 2007. Chlorine 
Yude,SA,dkk. 2016 Identifikasi dan Penentuan Kadar Klorin Pada Beras Yang Dijual Di Pasar Raya Padang. Jurnal Kesehatan Andalas. 5(3):653-655 